\title{
Pequeno mapa conceitual para a discussão do abuso e das relações abusivas em psicanálise ${ }^{12}$
}

\section{Eugênio Canesin Dal Molin ${ }^{3}$}

Pretendo sintetizar algumas ideias, que julgo interessantes para pensar sobre nosso tema, com o objetivo de desenhar um mapa conceitual útil para a discussão que virá a seguir. Longe de ser ostensivamente detalhado, o mapa talvez sirva como uma lista desigual de possíveis linhas de partida, e de passagem, antes de deitar a sola do pé no caminho.

Tenho trabalhado com pacientes que sofreram os mais diversos tipos traumas, e parte de minhas pesquisas, ao menos a realizada no âmbito acadêmico, voltou-se para a tentativa de compreender como se forma um trauma, quais seus efeitos, e quais aspectos do posicionamento do analista poderiam contribuir ou não no trabalho com os pacientes. A constante intersecção entre teoria e clínica permaneceu em vista quando me dediquei, recentemente, ao estudo de um tipo específico de situações, aquelas que traziam o fenômeno da violência para a clínica.

O primeiro conceito de nosso mapa é o de trauma psíquico. Sabemos que dois grupos de fenômenos orientaram as pesquisas psicanalíticas a respeito a seu respeito: as experiências de abuso sexual infantil e as neuroses de guerra; estas ora relacionadas, ora não, às neuroses traumáticas. Dos casos de abuso ou sedução, aprendemos que a temporalidade psíquica envolve uma atribuição posterior de significado a experiências que, de início, não mereceram, em si mesmas e assim que ocorreram, o atributo de

\footnotetext{
${ }^{1}$ Uma parte do material que compõe este texto foi colhida da tese $O$ caderno de Wassily: um estudo sobre a violência na clínica psicanalítica (Dal Molin, 2018) (DOI: 10.11606/T.47.2018.tde-04092018-170241), defendida no Departamento de Psicologia Experimental do Instituto de Psicologia da USP, com bolsa CNPq.

${ }^{2}$ Este trabalho foi apresentado na mesa "Quando o outro é ninguém: abuso e relações abusivas" com Eliana da Silveira Cruz Caligiuri no I Simpósio Bienal "O mesmo, o outro: Psicanálise em movimento" da Sociedade Brasileira de Psicanálise de São Paulo.

${ }^{3}$ Psicanalista, mestre e doutor pelo Instituto de Psicologia da USP.
} 
traumáticas. Ou seja, o trauma, como observado nessas situações - e como Freud destacara - tem em sua formação uma temporalidade própria, que pode ser decomposta em ao menos dois tempos com características diversas. $\mathrm{O}$ primeiro tempo arma-se quando de uma experiência de interação com os objetos externos que move o psiquismo, em sentido amplo. Eventualmente, essa experiência é seguida por outra, de natureza semelhante ou relacionada à primeira, que atribui àquela anterior um caráter disruptivo. Estaríamos, portanto, frente a um segundo tempo da formação do trauma, que foi bastante explorado por todos os autores que procuraram discutir tanto o trauma psíquico quanto a temporalidade em psicanálise.

Das neuroses de guerra e das neuroses traumáticas, por outro lado, aprendemos que, quando ocorrem episódios de susto ou quando os estímulos externos ultrapassam certa medida de intensidade, o psiquismo pode sofrer uma profunda alteração econômica. Seriam traumas psíquicos causados em um momento de rompimento da camada de proteção contra estímulos, como Freud (1920) argumentou de modo claro em Além do princípio do prazer. Entre os efeitos desse rompimento, encontramos o recuo do princípio do prazer e a tentativa de ligar psiquicamente cargas de excitação, de dominálas; trabalho que ganha uma de suas primeiras formas na passagem da posição passiva à posição ativa. É o caso da brincadeira do fort-da, apresentada e discutida por Freud depois de observar seu neto; mas é também o movimento interno notado em soldados que, após terem sofrido um trauma mecânico - uma experiência para a qual estavam despreparados - começam a exibir hiperestesia: uma hipersensibilidade sensorial aos estímulos que, se estivesse presente quando passaram pelas situações de grande estimulação, talvez fosse capaz de evitar o susto ou o choque. A passagem da passividade à atividade recebe nesses casos uma forma física.

Com Ferenczi (1932/1988, 1932-1933) as possibilidades de formação traumática ganham ainda outra organização. A elasticidade da técnica, que passara a adotar no fim da década de 1920, conduzia seus pacientes a um estado maior de relaxamento em que vivências traumáticas eram repetidas durante as sessões. $\mathrm{Na}$ verdade, tais repetições eram encorajadas pelo analista húngaro, acreditando que, por meio delas, um material muito primitivo, a origem mesma da condição patológica - de "conflito entre o Eu e seu 
ambiente" (Ferenczi, 1931, p. 160) -, poderia ser expresso e ganhar, pela primeira vez, acesso à percepção e à memória. Disso resultavam estados de profunda regressão, de transe muitas vezes, em que o paciente reproduzia a situação traumática com os afetos e reações que tivera quando da experiência original. A hipótese terapêutica do autor - de que as mudanças técnicas levariam à reprodução do trauma e a uma subsequente neocatarse proporcionada pela análise (Ferenczi, 1930) - não se confirmou. Muitos pacientes, observou, "começaram a sofrer de ataques noturnos de angústia, mesmo de graves pesadelos, e a sessão analítica degenerava repetidamente para um ataque de angústia histérica" (Ferenczi, 1932-1933, p. 157). Presenciando o desespero, que ganhava formas corporais, e ouvindo o que diziam os pacientes durante as sessões e sobre como se sentiam nos intervalos entre as sessões, Ferenczi passou a se dedicar profundamente à investigação de como o trabalho analítico podia agir nesses casos.

Em seu Diário, numa entrada do dia 30 de julho de 1932, Ferenczi divide o trauma em dois momentos, ou tempos, que chama de "Duplo choque" (1932/1988, p. 182). O primeiro choque seria o da experiência traumática inicial: nos casos de abuso, da confusão de línguas entre a criança e os adultos a respeito do que cada um espera do contato (terno para a primeira, passional para os últimos); e, nos casos de violência, da eclosão da paixão raivosa e agressiva do adulto sobre a criança, que não consegue integrar a situação em seu $\mathrm{Eu}$. $\mathrm{O}$ segundo choque seria resultado da negação (desmentido), do não reconhecimento, pelo agressor ou por um outro adulto, do abuso e da violência vividos pela criança. $O$ que se opera nesses dois choques, mas especialmente no segundo, é uma experiência de abandono radical. De acordo com o psicanalista húngaro, os efeitos seriam da ordem de uma "desintegração" defensiva, verdadeira cisão do Eu que poderia chegar à fragmentação ou à atomização caso os momentos de choque repitam-se (Ferenczi, 1932/1988; 1932-1933).

Num trabalho anterior (Dal Molin, 2016), propus que tal organização do conceito de trauma psíquico, se articulada com aquela empreendida por Freud, revelava um processo de formação traumática dotado de temporalidade própria, que não poderia ser circunscrito sempre a um evento economicamente disruptivo, nem aos efeitos de duas cenas relacionadas, em que a primeira é resignificada pela segunda, e nem a um duplo 
choque. Pareceu-me necessário considerar as variadas maneiras de formação do trauma, enfatizando, todavia, alguns aspectos do segundo entre os dois choques ferenczianos; um tempo do trauma capaz de trazer à tona o aspecto intersubjetivo desse processo, e que escapara a Freud. Propus também que esse tempo de busca por reconhecimento, potencialmente favorecedor de ligações e de domínio, era intermediário entre o primeiro choque e sua posterior ressignificação. Pareceu-me que lhe cabia a alcunha de terceiro, por ter sido localizado e discutido pelo próprio Ferenczi depois da identificação, por Freud, dos outros dois tempos da formação traumática. A nomeação desse tempo como terceiro, gostaria de enfatizar, deve-se à história da teorização; caso o intuito seja descrever a sequência de processos intrapsíquicos e intersubjetivos envolvidos na formação do trauma, talvez seja mais interessante chama-lo de "intermediário". De minha parte, gosto de conservar a perspectiva histórica. O resultado da articulação, de todo modo, comportava pensar o papel do analista frente às experiências de natureza disruptiva vividas pelo paciente e narradas ou reexperimentadas transferencialmente durante a sessão.

O segundo conceito que julgo útil ao nosso mapa é o de violência, em especial quando o utilizamos junto ao trabalho clínico. As categorias de trauma e violência não são, no plano teórico, ligadas de maneira evidente e direta; mas quem atende vítimas de violência tem poucas dúvidas de que o trauma é um aspecto definidor daquilo que os pacientes vivem e dos efeitos psíquicos que são gerados pela experiência de violência . Mais do que isso, o clínico não tarda a perceber que se arma, na dinâmica transferencial-contratransferencial, um jogo que continuamente remete às situações de violência e às posições ocupadas pelo paciente quando as viveu. Somos introduzidos à compulsão à repetição envolvida no trauma e, por meio das narrativas que fazem os pacientes e dos movimentos transferenciais e contratransferenciais gerados, experimentamos de passagem, e em menor grau, a espessura de cada posição.

Num dos melhores livros que conheço sobre a clínica com vítimas de abuso sexuais, Object Relations in Severe Trauma, Stephen Prior (1996) fala em um "incansável reviver de experiências de vítima-vitimizador" (p. 62) no trabalho com seus pacientes: padrões que "frequentemente se tornam dolorosamente transparentes na brincadeira da 
criança, na qual há uma constante alteração entre papéis de perpetrador e vítima" (Pior, 1996, p. 63). Para Prior (1996), junto a esse incansável reviver, outros três aspectos são percebidos: o paciente apoia-se na identificação com o agressor como modelo básico de defesa psíquica; tem a convicção de que foi a causa do abuso (da violência), mereceu-a, e por isso é mau; e procura contato com os objetos por meio da violência física, da sexualidade, ou alguma combinação das duas (p.61-62). Cada um desses aspectos comporá, em graus variados, aquilo que, mais tarde, encontraremos na clínica.

Gostaria de acrescentar que mesmo os aspectos de natureza ativa, ou seja, que implicam a adoção de uma posição ativa nas reações ao trauma severo, trazem consigo o estofo da passividade. O reviver incansável das situações de vítima-vitimizador exibe essa ambiguidade, já que explicita como as duas posições podem ser ocupadas alternadamente e de maneira repetida. O mesmo pode ser depreendido no apoio sobre a identificação com o agressor como defesa básica - o terceiro conceito útil ao nosso pequeno mapa.

Quando Ferenczi (1932-1933) introduz o conceito na teoria psicanalítica, a identificação com o agressor é uma defesa autoplástica (de alteração do próprio Eu) que procura compreender e antever os desejos e vontades do agressor. A vítima identifica-se com o agressor para descobrir suas intenções, para não estar completamente passiva quando a situação armar-se outra vez. Por outro lado, ao antever seus desejos e vontades, pouco resta que não a submissão: o indivíduo passa a funcionar como um autômato, adapta-se ao agressor, numa dinâmica que termina por obscurecer a responsabilidade subjetiva pela ação. Percebamos como há uma passagem da passividade, na primeira experiência, à atividade, nas seguintes, mas essa atividade é, para o observador externo, um reestabelecimento da posição passiva, agora sem os efeitos da surpresa e do choque. Algo na mesma linha do processo interno que fora notado em soldados com hiperestesia após traumas de guerra.

Um elemento que ajuda na compreensão desse ilustrativo entrejogo entre passividade e atividade é a postulação de Fenichel (1939) a respeito de uma atitude contra-fóbica; que 
apresento como a quarta e última parada de nosso mapa. A atitude contra-fóbica procura nomear e explicar o paradoxo envolvido no fato de que, para diminuir a angústia temida em determinadas situações, algumas pessoas se submetem a experiências similares as que, da primeira vez, originalmente causaram a angústia. O problema, como podemos perceber, diz respeito à busca por situações de perigo, geradoras de angústia-sinal, nos termos de Freud (1926), que remetam à situação traumática de desamparo. Dito de outra forma: uma vez tendo vivido a situação traumática de desamparo, o sujeito retorna posteriormente a ela, na tentativa de dominá-la, e coloca-se ativamente num lugar capaz de gerar angústia-sinal e não desamparo. Fenichel acrescenta um elemento à leitura:

Quando o organismo descobre que agora é capaz de vencer sem medo a situação que antes o teria sobrecarregado de angústia, ele experimenta um certo tipo de prazer. Este prazer tem o caráter de "Não preciso mais sentir angústia". Faz a brincadeira da criança evoluir de uma descarga imediata ao domínio do mundo exterior por meio do exercício repetido (Fenichel, 1939, p. 166).

Fenichel está cônscio dos ganhos trazidos pela passagem da passividade à atividade, da compulsão à repetição envolvida nesse ímpeto, mas procura destacar também outros aspectos. A atitude contrafóbica traz a sensação de triunfo, sentida como prazer ao vencer o medo da situação, e pode envolver também, no caso de crianças, o "deixar que uma pessoa amada, em quem confiam, faça com elas o que temem fazer a si mesmas" (Fenichel, 1939, p. 169). Algo que poderia ser expresso pela frase: "Vamos brincar daquilo que eu tenho medo". Fenichel ainda chama a atenção a outros aspectos interessantes, entre os quais 'uma verdadeira 'libidinização do medo', que ocorre com pessoas que atravessaram certo desenvolvimento masoquista" (Fenichel, 1939, p. 170) e o fato de que mesmo o triunfo prazeroso não é integral; ocorrem vazamentos de destrutividade que subitamente acionam a antiga angústia e causam desprazer. Seria o caso de alguém que, em meio à enésima encenação ativa de algo tenebroso que viveu, tem um vislumbre do terror que sentiu quando da experiência original, e hesita.

Nos casos de abuso, em que o trauma e a violência ditam o ritmo do compasso no trabalho clínico, a dinâmica transferencial-contratransferencial intensifica a percepção de que as passagens da posição passiva à posição ativa envolvem uma - nem sempre 
discreta - esperança na capacidade do objeto de oferecer novos elementos de ligação. Mesmo que saibamos que tal percepção não é mais do que o começo do trabalho, não se trata de pouca coisa

\section{Referências}

Dal Molin, E. C. (2016). O terceiro tempo do trauma: Freud, Ferenczi e o desenho de um conceito. São Paulo, SP: Perspectiva/FAPESP.

Dal Molin, E. C. (2018). O caderno de Wassily: um estudo sobre a violência na clínica psicanalítica. Tese de Doutorado, PSE - Instituto de Psicologia, Universidade de São Paulo. (DOI: 10.11606/T.47.2018.tde-04092018-170241). Disponível em: http://www.teses.usp.br/teses/disponiveis/47/47132/tde-04092018-170241/pt-br.php

Fenichel, O. (1939). The conter-phobic attitude. In O. Fenichel, The collected papers of Otto Fenichel: Second series (H. Fenichel \& D. Rapaport, eds., pp. 163-173). New York, NY: W. W. Norton, 2014.

Ferenczi, S. (1930). The principle of relaxation and neocatharsis. In S. Ferenczi, Final contributions to the problems and methods of psycho-analysis (M. Balint, ed., E. Mosbacher et al., trads., pp. 108-125). London: Karnac, 2002.

Ferenczi, S. (1931). Child analysis in the analysis of adults. In S. Ferenczi, Final contributions to the problems and methods of psycho-analysis (M. Balint, ed., E. Mosbacher et al., trads., pp. 126-142). London: Karnac, 2002.

Ferenczi, S. (1932/1988) The clinical diary of Sándor Ferenczi (J. Dupont, ed., M. Balint \& N. Z. Jackson, trads.). Cambridge, MA: Harvard University Press.

Ferenczi, S. (1932-1933). Confusion of tongues between adults and the child: The language of tenderness and of passion. In S. Ferenczi, Final contributions to the problems and methods of psycho-analysis (M. Balint, ed., E. Mosbacher et al., trads., pp. 156-167). London: Karnac, 2002.

Freud, S. (1920). Além do princípio do prazer. In S. Freud, Obras completas (Vol. 14, pp. 161-239). São Paulo, SP: Companhia das Letras, 2010. 
Freud, S. (1926). Inibição, sintoma e angústia. In S. Freud, Obras completas (Vol. 17, pp. 13-123). São Paulo, SP: Companhia das Letras, 2014.

Prior, S. (1996). Object relations in severe trauma: Psychotherapy of the sexually abused child. Northvale, NJ: Jason Aronson. 